\section{Biomechanics in Sport}

Papers prepared for the Engineering in Medicine Group of the Institute of Mechanical Engineers

Mechanical Engineering Publications: London, 1988. $210 \times 296 \mathrm{~mm} .121$ pages. Illustrated in black-and-white. $£ 28.00$ softback

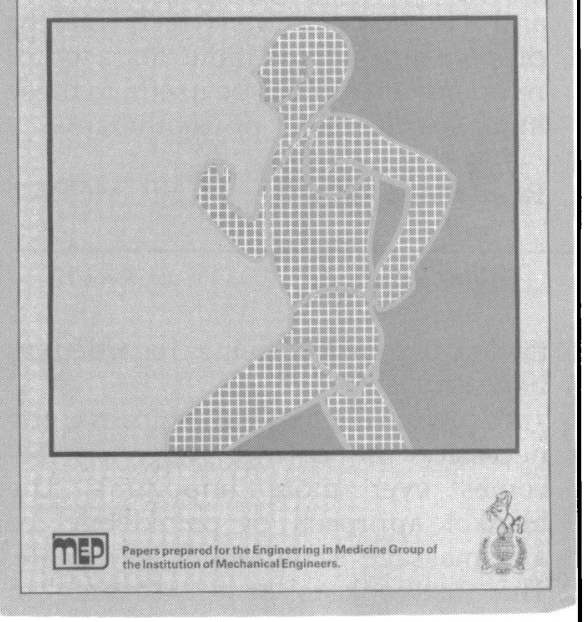

This book comprises 19 papers from a conference organized by the Institute of Mechanical Engineers which was eventually never held. The subjects covered can be broadly divided into analysis of equipment, papers of a more medical bias, and papers concerned with the analysis of sporting activity. The three papers concerned with the analysis of equipment include one which is a broad overview of safety aspects relating to equipment design.

There are five papers in this volume concerned with medical aspects of sport, of which three were concerned with the knee. A system for knee meniscus injury evaluation using a non-invasive vibration-based arthroscopic technique is described in one paper. Another describes and evaluates a new arthrometer for the quantitative assessment of ligamentous structure of the knee joint. Tying in well with these papers is an examination of the variation in retropatellar force as a consequence of three types of surgery on the knee using cadavers.

Running is the subject of seven of the 11 papers concerned with the analysis of sporting activities. These papers include a review paper on the effects of wind resistance on sprinting performance. One paper quantifies the three-dimensional resultant joint moments at the knee during running, while another paper in a similar vein examines the different forces associ- ated with those runners who strike the ground with the rear part of the foot first and those who strike it initially with the front of their foot. Different experimental procedures can be used to examine the physiological costs of running, and there is an interesting paper which compares the temporal and kinematic parameters associated with running over ground, with running on both a motorized and nonmotorized treadmill. This paper is a useful preliminary investigation of these running activities. A force plate analysis of the frequency content of hurdling and running presents findings which have significant implications for experimental design when investigating both of these activities. An analysis of the feet of cadavar specimens is reported which attempts to quantify the energy savings during running due to the arch of the foot. Another paper attempts to elucidate the role of mono-articular and biarticular muscles in the energetics of

Flexibility - How To Understand It, How to Achieve It

Paul McNaught Davis

Transworld Publishers: London, 1991. $254 \times 192 \mathrm{~mm}$. 146 pages. Illustrated. $£ 14.99$

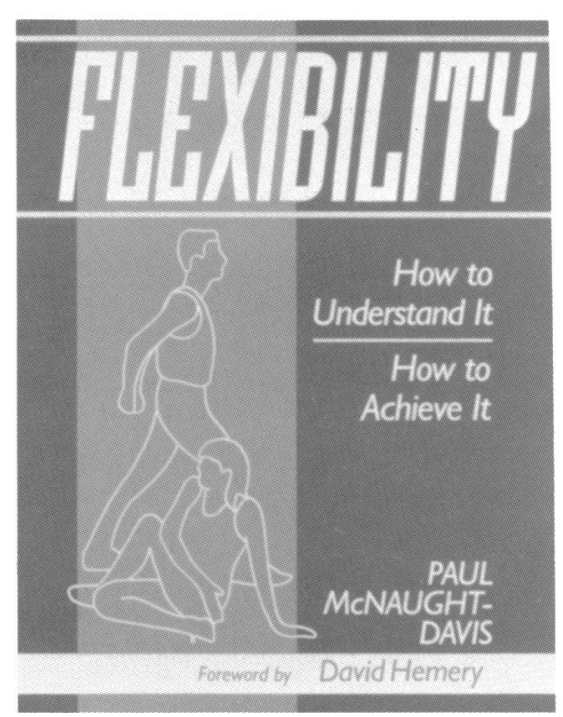

At the compulsive 'flicking'. through stage of examining Paul McNaught Davis' book Flexibility, one may be forgiven for looking forward to reading it. It is an attractively well set out book with simply described illustrations and bold lettering for important issues.

The author does not make it clear who this book is targeted at, but it is possible the athlete or club coach may make useful reference to it. The author both broadly and elaborately describes flexibility. However, the book lacks detail and critique and these coupled the swing phase of sprinting.

The work reported by most of the papers is original, and as such this compilation has some merit. Certain papers use methodological designs and experimental procedures which are less than optimal so their results must be viewed with caution. The papers are produced from camera ready form, and are variable in format and in quality of print, particularly frustrating from this point of view is that in some papers the diagrams are in the main body of the text while for other papers they are gathered together at the end of the paper. At a cost of $£ 28.00$ for the 121-page book it should be stocked in the libraries of most institutions of higher education, but at this price and with the variable content the book is not necessarily recommended for the personal library of interested researchers.

\section{John H. Challis PhD}

with its long-winded, rambling style make it unlikely to become the 'bible' on flexibility, as suggested.

A simplified version of physiology and principles of stretching include reasons for caution during maturation and ageing. The special problems of the over 25-year olds, being the obvious target group, should also have been highlighted. The author distinguishes between plastic and elastic deformation of muscle connective tissue and methods of effecting these. He made no mention however, of cryotherapy and its use to provide permanent changes in muscle length as pointed out in the recent North American literature.

Further to this, I was disappointed not even to find 'hold relax' methods named in the text, with the author advocating PNF stretching techniques for advanced stretching only. Auto hold-relax techniques are more likely to be safely controlled than support or stretch provided by coach or fellow athlete.

Unfortunately, I have to mention that this is not a book I would personally recommend to coach or patient. The author's chapter on home stretching panders completely to the athletes' ease and home routine. For instance, gröin stretches on a soft settee provide little support to an already slouched back. Finally, many of the slow static stretches as illustrated were out of date and cause too much strain on the back and may even cause a problem to the healthy sportsman.

\section{R. Macdonald BA, MCSP, MCPA}

